\title{
Consumidores e agricultura orgânica em Portugal: significados e (des)confiança.
}

Mónica Truninger ${ }^{2}$

\section{Resumo}

Nos últimos anos do corrente século, o sector da agricultura orgânica tem visto as suas áreas de produção, cotas de mercado e número de consumidores a crescer. Na União Europeia, o enquadramento legal desse modo de produção data do início dos anos 90 do século $\mathrm{XX}$, mas ao longo dos anos essa legislação tem sido alvo de várias alterações. Apesar de um enquadramento legal apertado, surgem, por vezes, situações de fraude ou controvérsia em torno da fiscalização e certificação dos produtos orgânicos. As falhas dos sistemas periciais, técnicos e científicos no controlo e monitorização da produção alimentar orgânica, mesmo que ocorram excecionalmente, quando são divulgadas pelos media acabam por aumentar, junto dos consumidores, a desconfiança e a falta de credibilidade na origem de produção desses alimentos. Neste texto, com base em dados qualitativos e quantitativos, analisam-se os significados que os consumidores têm sobre os produtos orgânicos, muitas vezes confundindo-os com os produtos que cultivam em casa ou que lhes são oferecidos pelas suas redes familiares, de amigos e vizinhos. Também se analisam os mecanismos de construção de uma relação de confiança com os alimentos orgânicos, que passam tanto pelo conhecimento pericial inscrito num certificado e num logótipo como também pelo conhecimento tácito, leigo, experiencial e sensorial que têm com esses alimentos no seu quotidiano. Conclui-se que os consumidores usam diferentes e múltiplas estratégias, conjugando

I Secções deste texto têm por base o artigo "As bases plurais da confiança alimentar nos produtos orgânicos: da certificação ao 'teste da minhoca”" (TRUNINGER, 2013, p. 81-102). O presente texto sofreu substanciais adaptações, contendo partes totalmente novas para apoiar melhor os argumentos defendidos. Os dados sobre agricultura orgânica baseiam-se num trabalho de equipa mais vasto no âmbito do Segundo Grande Inquérito sobre Sustentabilidade. Estou grata à equipa constituída por Luísa Schmidt, João Graça, Susana Fonseca, Luís Junqueira e Pedro Prista. Um especial agradecimento ao Luís Junqueira, por ter elaborado uma primeira análise dos dados qualitativos dos grupos focais, os quais foram utilizados, adaptados e reescritos para este texto. O inquérito foi realizado com o apoio da Missão Continente do grupo Sonae.

2 Doutorada em Sociologia pela Universidade de Manchester (Reino Unido). Investigadora auxiliar no Instituto de Ciências Sociais da Universidade de Lisboa, onde coordena vários projetos nacionais e internacionais na área da alimentação, consumo e sustentabilidade.

$(\mathrm{cc}) \mathrm{Br}$

Direito autoral e licença de uso: Este artigo está licenciado sob uma Licença Creative Commons. Com essa licença você pode compartilhar, adaptar, para qualquer fim, desde que atribua a autoria da obra, forneça um link para a licença, e indicar se foram feitas alterações. 
o conhecimento pericial com o conhecimento mais leigo, para se assegurarem de que o que ingerem nos seus corpos são mesmo produtos orgânicos.

Palavras-chave: Agricultura orgânica. Consumidores. Desconfiança. Sistema alimentar. Significados de produtos orgânicos.

\section{Introdução}

Nas décadas finais do século XX, e nas primeiras do século vigente, surgiram vários escândalos alimentares na Europa, sendo Portugal também afetado por essas crises. Problemas como a BSE (ou, vulgo, 'crise das vacas loucas'), febre aftosa, gripe das aves, a fraude da carne de cavalo, entre outras, tornaram-se a face visível de processos mais latentes que vinham paulatinamente a acentuar-se desde o pós-guerra: a intensificaçấo da produção agroalimentar; a concentração de poder nas grandes redes varejistas e a consequente marginalizaçáo da agricultura familiar de pequena escala; a configuraçấo de novas dinâmicas espaciotemporais que fizeram provocar alteraçôes nos limites naturais da sazonalidade e frescura; a crescente separação entre produçáo e consumo nos espaços cartográficos e cognitivos; entre outras mudanças (TRUNINGER, 2013, p. 81).

Essas reconfiguraçôes no sistema alimentar aumentaram a pressáo para a emergência e aceleraçáo de cadeias alimentares curtas e alternativas, sendo a agricultura orgânica um dos sistemas de produção agrícola que ganharam substancial projeçáo na Europa e no resto do mundo. A agricultura orgânica é um sistema de produção agrícola e pecuário que tenta minimizar os impactos sociais e ambientais no planeta, através da forma de cultivo, dos usos eficientes da água, das restriçôes na aplicação de químicos sintéticos nas plantas e de antibióticos e hormonas nos animais, dos cuidados com o solo e do respeito pelos princípios do bem-estar animal. Esse sistema de produção agropecuário vem, de certo modo, em conjunto com outras alternativas alimentares (e.g., reduçấo da proteína animal, Dieta Mediterrânica), responder aos apelos para a implementação de uma transformação profunda dos hábitos alimentares globais (ver o relatório da comissão EAT Lancet, WILLETT et al., 2019). Essas preocupaçôes têm em conta não só os impactos da alimentação na saúde humana, como também os impactos da produção agrícola no ambiente e o contributo que esta tem para o aumento dos gases com efeito de estufa, no cenário atual de alteraçôes climáticas (GRAÇA et al., 2019). 
$\mathrm{Na}$ Europa, o modo de produção orgânico está legalmente enquadrado através do regulamento do Conselho (EC) no 834/2007, de 28 de junho de 2007, sobre produção e rotulagem, o qual veio revogar o Regulamento (EEC) no 2092/91. O atual regulamento, de 2007, será em breve substituído por um novo - Regulamento (EU) no 2018/848, do Parlamento Europeu e do Conselho de 30 de maio de 2018 -, o qual entrará em vigor em 2021. Este enquadramento legal promoveu uma aposta cada vez maior na agricultura orgânica, tanto na Europa como em Portugal. Só para se ter uma noção do impacto desse sector no nível da produção e consumo, dados disponíveis para o ano de 2017 apontam para a existência de 69,8 milhóes de hectares de área agrícola no modo de produção orgânico em nível mundial. Na Europa, essa área era, naquele ano, de 12,6 milhóes de hectares, representando $18 \%$ da área agrícola global e $7 \%$ da área europeia. Nos últimos dez anos, o crescimento da produção orgânica foi de $70 \%$, o que reflete a enorme importância desse sector. No que concerne ao valor desse mercado mundial, em 2017, o sector atingiu 92 mil milhôes de euros; já na Europa, representou 34,3 mil milhôes de euros (COMISSÃO EUROPEIA, 2019).

O mercado continua em forte crescimento, duplicando o seu tamanho na última década, indiciando que ainda está longe da sua maturação. A Alemanha e a França são os mercados mais desenvolvidos e maduros nesse sector, e as grandes redes varejistas são importantes para impulsionar o mercado, nomeadamente na Áustria, Dinamarca e Suécia. Em Portugal e Espanha, são sobretudo as lojas especializadas que dominam a comercialização e distribuição desses produtos aos consumidores, sendo ainda considerados mercados de nicho (COMISSÃO EUROPEIA, 2019, p. 3-9). Em Portugal, em 2017, havia 283.079 hectares e 4.288 produtores, sendo Trás-os-Montes e o Alentejo onde existia maior número de operadores nesse sector (Direçáo Geral de Agricultura e Desenvolvimento Rural, dados acedidos em 28 de janeiro de 2019). O inquérito nacional à alimentação e atividade física realizado em 2015/2016 reportou que esses produtos certificados são consumidos por $11,6 \%$ da populaçáo adulta nacional, mais frequentemente pelas mulheres $(13,1 \%)$ e menos pelos idosos $(5,5 \%)$. Os produtos hortícolas e a fruta orgânica são os mais consumidos pelos portugueses (LOPES et al., 2017, p. 77). 
Esses dados mostram o crescimento tanto da produção como do mercado, bem como a adesão crescente dos consumidores a esses produtos que, no geral, consideram ser mais saudáveis e melhores para o ambiente (TRUNINGER, 2010). Mas será que existem diferentes entendimentos e significados de produtos agrícolas orgânicos pelos consumidores? Como se estabelece a confiança nesses produtos?

Sabemos que, nos últimos anos, tem havido alguns escândalos em torno dos produtos orgânicos que têm minado a confiança nos mesmos. Algumas notícias mediatizadas na última década deram conta de irregularidades, fraudes e infrações cometidas na produção e certificação desses alimentos, aumentando a desconfiança nestes. $\mathrm{O}$ governo português aprovou a Estratégia Nacional para a Agricultura Biológica e o Plano de Ação para a produção e promoção de produtos agrícolas e géneros alimentícios orgânicos em julho de 2017, estando entre as preocupaçôes o investimento no sector e o aumento da confiança nos sistemas de certificação e monitorização dos produtos orgânicos, de forma a que estes não contenham substâncias químicas sintéticas ilegais. Nesse sentido, este artigo procura saber, através de dados qualitativos e quantitativos, quais os significados dos portugueses sobre os produtos orgânicos e que mecanismos de confiança utilizam no seu quotidiano na aquisição e uso desses produtos.

Após uma breve revisão de literatura sobre os diferentes conhecimentos periciais e leigos utilizados para construir uma relação de confiança com esses produtos (esquemas de certificação e rotulagem; relaçôes interpessoais; conhecimento experiencial e prático na utilização desses produtos; conhecimento sensorial), apresentamos os procedimentos metodológicos que servem de base aos resultados apresentados. Aqui utilizamos os dados de três grupos focais realizados antes da aplicação do Segundo Grande Inquérito sobre Sustentabilidade, em 2018. A seguir, mostramos que os consumidores têm diferentes entendimentos de produtos orgânicos e formas diversas de construir uma relação de confiança com eles. Também verificamos que consultam muito pouco os rótulos quando vão às compras alimentares, porém o símbolo europeu da agricultura orgânica é o mais reconhecido.

As formas diversificadas que os consumidores encontram para confiar nesses produtos - desde a confiança interpessoal no produtor, à relação 
mais experiencial e sensorial com os alimentos, até à confiança institucional através do rótulo - respondem de certa forma às controvérsias sobre a credibilidade desses produtos no mercado. Concluímos que os sistemas periciais, técnicos e de base científica de salvaguarda desses bens alimentares (e.g., o rótulo, a certificação) não são, por si sós, suficientes para aplacar as inquietações e desconfianças dos consumidores nos produtos 'bio'. $\mathrm{Ou}$ tros mecanismos de teor mais leigo, que não passam pela certificação ou por procedimentos técnico-científicos, surgem para aumentar a confiança nesses bens. Estes passam pelas relaçóes interpessoais e pela experiência sensorial quotidiana com os alimentos 'bio'.

\section{Os estudos sociais da confiança alimentar}

Os estudos de ciências sociais sobre a confiança alimentar são volumosos. Kjaernes, Harvey e Warde (2007) definem a confiança como uma propriedade emergente das instituiçóes, articulando três importantes processos relacionais: varejo alimentar (mercado), consumidores e Estado. É nas relaçóes que se estabelecem entre essas três entidades que a noção de confiança é configurada e negociada. Nesse sentido, a confiança é sobretudo social e relacional (TRUNINGER, 2013).

Esses autores situam o conceito de confiança nas configuraçóes institucionais, o que vai além das perspectivas mais individualistas e cognitivistas. Estas últimas entendem a confiança como resultante de processos cognitivos articulados à avaliação de risco e à percepção de falhas na segurança alimentar. De forma a colmatar essas falhas, parte-se da premissa de que quanto mais informação os indivíduos possuírem sobre o funcionamento dos mecanismos de transparência, regulação e governança alimentar, mais confiança terão nos produtos alimentares que consomem.

Assim, é central a credibilidade nas fontes de informação, sendo que a desconfiança aparece quando há falhas de comunicaçáo sobre os riscos. Sempre que os indivíduos fazem escolhas que colocam em risco a sua saúde, os defensores dessa perspectiva mais individualista entendem que a razão principal é os consumidores estarem mal informados ou serem ignorantes na matéria. Esse é um tipo de raciocínio que privilegia o modelo do déficit de informação, isto é, a legitimidade e domínio do saber 
especializado sobre outros saberes (e.g., local, leigo, tácito, experiencial) (GUIVANT, 1998; TRUNINGER, 2013). Essa abordagem mais individualista assenta na premissa do fornecimento de informação como forma de ultrapassar potenciais quebras de confiança. Porém, nem sempre informar os consumidores sobre um determinado risco se traduz no aumento da sua credibilidade no sistema alimentar.

Outra leitura que pode ser feita sobre os processos de confiança e desconfiança articula-se ao conceito da 'sociedade de risco' e do crescente processo de individualização, ideias propostas por Beck (1992). À medida que se caminha para uma sociedade coabitada por riscos modernos que se alastram à escala mundial, torna-se praticamente impossível estimar o aparecimento deles, sendo o seu controle difícil de implementar. De acordo com essa leitura, os processos de insegurança e de desconfiança são tônicas importantes e caracterizadoras das sociedades de risco (TRUNINGER, 2013).

Uma terceira perspectiva de confiança, avançada por Misztal (1995), é a que a articula aos valores morais, coesão social e sentido de comunidade cultural. Através de normas que guiam a ação social, geram-se estabilidade, ordem e confiança na previsibilidade do comportamento dos outros. Esses indivíduos se comportam de forma expectável, e essa expectativa transmite confiança. Ao contrário, a desordem está associada ao caos e à desconfiança. Segundo uma leitura funcionalista, a confiança é uma peça fundamental para manter a ordem social (TRUNINGER, 2013). Tendo em conta uma perspectiva mais cultural e normativa, a confiança é conceitualizada no seio de normas, valores e rotinas que se perpetuam no tempo. O caráter habitual e rotineiro das práticas alimentares reforça a confiança irrefletida que pode ser uma forma de o consumidor lidar com a complexidade do sistema agroalimentar. Só quando acontece algo de inesperado é que se entra em processos de reflexividade crítica, e se procura saber as razóes para a ruptura da normalidade.

É nessas situações de ruptura da normalidade que a confiança reflexiva proposta por Bildtgard (2008) é útil. Esta surge sempre que uma situação crítica aparece, a qual perturba a forma habitual com que as coisas são feitas, provocando ruptura ou instabilidade no sistema, ou quando o 
consumidor é confrontado com novas formas de fazer e conhecer que colocam em causa as suas certezas. Nesse sentido, a confiança já não é algo que se tome por garantido, mas tem de ser ativamente negociada e demonstrada. Por exemplo, após uma crise de segurança alimentar, os vários atores intervenientes mobilizam esforços para tornar as suas operaçóes mais credíveis aos olhos do consumidor.

Outra leitura da confiança, mais centrada nas teorias institucionalistas, entende esse conceito como estando interligado com o desempenho político ou institucional de atores ou organizaçóes. Assim, a confiança emerge no cumprir de responsabilidades que são delegadas a órgãos institucionais, para que os produtos alimentares mantenham os critérios de qualidade esperados pelos cidadãos. As práticas de certificação e inspeção sanitária poderão tranquilizar os consumidores acerca da credibilidade dos produtos alimentares, reforçando mecanismos de confiança institucional (ou confiança sistêmica) (KJAERNES; HARVEY; WARDE, 2007; LUHMANN, 1979). Nas sociedades contemporâneas, em que os riscos e as incertezas abundam, os indivíduos têm de relegar para sistemas abstratos a responsabilidade de assegurar a qualidade e a segurança alimentares (GIDDENS, 1990). Alguns exemplos desses sistemas são a ciência, as autoridades reguladoras, as agências de certificação e inspeção alimentar e a rotulagem.

Sassatelli e Scott (2001) distinguem dois tipos de confiança: aquela que se encontra ancorada nas instituiçóes ('confiança desembutida' ou disembedded trust); e a confiança fundada na rede de relaçóes interpessoais e de saber local ('confiança embutida' ou embedded trust). No primeiro tipo - confiança desembutida -, as organizaçóes formais são o mecanismo por excelência para o estabelecimento da confiança alimentar. Os esforços organizacionais para tornar o sistema agroalimentar mais transparente (e.g., inspeção, rotulagem, certificação) fazem parte das diversas tecnologias que os sistemas de governança têm a seu dispor para manter a confiança alimentar dos consumidores.

No segundo tipo - confiança embutida -, é através das relaçôes próximas entre produtores e consumidores que se reduzem a complexidade e a incerteza do sistema alimentar, e se aumentam a confiança e a transparência nos processos de produção. É de frisar que as noçóes de confiança 
aqui expostas colocam a tônica no fato de esta emergir de relaçóes sociais, atravessadas por relaçóes interpessoais e por relaçôes institucionais. No estudo sobre os consumidores de agricultura orgânica realizado em Lisboa no início dos anos 2000, Truninger (2013) verificou a existência de um outro tipo de confiança, emergente das relaçóes entre corpos, alimentos e as experiências quotidianas alimentares. Nesse estudo, através da análise de 30 entrevistas com consumidores de produtos orgânicos, constatou-se que as bases para a confiança alimentar são heterogêneas e multidimensionais. Vários participantes colocavam menos valor na necessidade de um rótulo que provasse a certificação dos produtos orgânicos quando estes eram adquiridos através de uma relação próxima com o produtor/retalhista.

Os participantes valorizavam ainda a experiência pessoal com os produtos; a honestidade e credibilidade do produtor; as redes sociais estabelecidas dentro dos contextos de venda; e o sentimento de pertença a uma comunidade que partilha os mesmos valores e visóes do mundo. Porém, foi igualmente fundamental a confiança habitual nos produtos alimentares, construída através da avaliação da presença de propriedades não humanas, realizada cotidianamente através de testes que configuram a autenticidade e a confiança dos produtos orgânicos (ROE, 2006). Por exemplo, alguns consumidores valorizaram as características estéticas, sensoriais, metabólicas e a presença ou ausência de bichinhos que preenchem as expectativas do que qualificam como orgânico: sem uma aparência polida, resplandecente e artificial; conservando-se durante mais tempo; com animais e/ou seus rastros (TRUNINGER, 2013, p. 95). É assim proposta uma outra noção de confiança que se constrói através da permanente e incessante ordenação de diversos elementos heterogêneos, sendo um fenômeno relacional e situado, em vez de algo que só tem presença e legitimidade nas relaçôes sociais entre pessoas, ou entre pessoas e instituiçóes. Nesse sentido, é importante considerar a materialidade das relaçóes de confiança para se definir, de forma mais abrangente e precisa, o próprio conceito de confiança alimentar.

\section{Metodologia e técnicas de recolha de dados}

Este trabalho baseia-se em duas técnicas de recolha de dados que foram mobilizadas em duas fases distintas. Numa primeira fase, realizámos 
três grupos focais com duração aproximada de duas horas cada um, realizados entre os dias 11 e 14 de junho de 2018, conduzidos com base num guiáo semidiretivo. Os três grupos focais foram constituídos por residentes da Grande Lisboa, divididos entre um grupo de mães solteiras, mães com parceiro ou avós (sete pessoas); um grupo de homens e mulheres oriundos de famílias de baixa renda (oito pessoas); e um grupo de jovens entre 18 e 35 anos que não tinham filhos e que viviam sozinhos, em casal ou com amigos (oito pessoas). As três sessóes de grupo foram gravadas em áudio e vídeo e sujeitas a análise de conteúdo com base na audição integral das gravaçóes de áudio.

Numa segunda fase, foram coletados dados em entrevistas pessoais com 1.600 participantes, como parte de uma pesquisa nacional mais ampla sobre sustentabilidade em Portugal. A amostragem de cotas foi aplicada para garantir uma amostra demograficamente representativa em termos de gênero, faixa etária e localização geográfica. Entrevistadores profissionais do Institute of Marketing Research conduziram as entrevistas no ano de 2018, de 7 de novembro a 13 de dezembro, várias vezes durante o dia e a noite, durante a semana e fins de semana, usando tablets para registrar os dados (por exemplo, o software CAPI). Regióes e cidades foram selecionadas com antecedência para garantir a representação das diversas localizaçóes geográficas, e ruas, prédios e residências para as entrevistas foram selecionadas aleatoriamente. Os participantes de cada família também foram selecionados aleatoriamente usando o CAPI com base nas cotas de gênero e faixa etária (um participante por família). A amostra $(\mathrm{N}=1.600)$ estava bem equilibrada em termos de gênero (842 mulheres, 52,6\%; 758 homens, 47,4\%), com idade entre 18 e 90 anos $(M=48,30$; $\mathrm{DP}=16,35)$, e os participantes haviam concluído o ensino básico $(30,1 \%)$, ensino médio $(32,9 \%)$ ou ensino superior $(37 \%)$.

Os dados recolhidos, tanto qualitativos como quantitativos, respeitaram vários tópicos, como: orientaçôes, valores e práticas sobre as questôes do consumo e alimentação saudável e sustentável, economia circular, agricultura orgânica, segurança alimentar, produção local, desperdício alimentar, mudanças de práticas depois da crise económica, entre outras questóes. Neste artigo, debruçamo-nos sobretudo nas questóes referentes à agricultura orgânica. Os dados foram tratados através de vários procedimentos 
estatísticos, como simples frequências e cruzamentos até análise de clusters. Foram também tomadas todas as providências de foro ético, de forma a garantir a confidencialidade e anonimato dos dados recolhidos, tanto através dos grupos focais como através do inquérito.

\section{Significados e mecanismos de confiança: os grupos focais}

Para a maioria dos participantes dos grupos focais realizados em junho de 2018, a agricultura orgânica é definida como aquela que "não leva químicos" ou que leva o "mínimo de químicos possíveis".

É uma produção sem utilizar nada que venha de origem química, só se utiliza coisas de origem natural. (Grupo focal jovens sem filhos).

A minha mãe faz agricultura orgânica porque não usa produtos químicos, mesmo o fertilizante é só estrume. (Grupo focal de baixa renda).

Para além da associação da agricultura orgânica a uma ideia de 'natural' e 'sem químicos', seguem-se os significados que se articulam à pequena escala, a uma produção feita em casa, ou em espaço rural. Por vezes, essa agricultura mais 'familiar' e 'caseira' é considerada mais orgânica do que os produtos 'bio' vendidos no mercado. $\mathrm{O}$ acesso a produtos de produção caseira ou a pequenos produtores satisfaz como alternativa, tendo a vantagem, em geral, de o preço ser menor.

Justifica-se principalmente pelo tamanho dessas produções, associo a produção bio a uma quantidade menor, não ser uma produção em massa, mais limitada em quantidade, tem que compensar no preço... Essa produção é muito mais lenta, uma coisa em estufa é muito mais rápida... O trabalho que dá, o número de recursos humanos... (Grupo focal dos jovens sem filhos).

O facto de os consumidores saberem como se produzem os alimentos, de controlarem essa produçáo, faz aumentar o conhecimento e a confiança nos mesmos. De facto, alguns participantes admitiram que quanto menos sabem sobre o processo de produção dos produtos orgânicos, mais se instalam as dúvidas sobre aqueles. Existem por vezes inseguranças sobre o que é agricultura orgânica e, em alguns casos, as pessoas mostraram ceticismo sobre a possibilidade de produzir alimentos sem recorrer a pesticidas e fertilizantes químicos sintéticos. 
Eu não aceito essa coisa do bio, aquilo mesmo sendo pequenino tem que ter produto para os bichinhos não irem lá... (Grupo focal das mulheres com crianças).

Não usam tanto o químico, eu acho que é impossivel não ter, senão teria bicho! (Grupo focal de baixa renda).

Neste último excerto de entrevista, não ter bicho levanta ainda mais suspeitas. Quando há bicho, esse é um sinal relevante para a construção da relação de confiança com os produtos orgânicos, pois a sua presença é um indicador claro de que os alimentos não foram pulverizados com químicos sintéticos para matar o bicho. Quando os bichos não estão lá, os consumidores têm a prova de que foram provavelmente utilizados químicos sintéticos para fazer desaparecer o bicho. Nesse sentido, o conhecimento sobre os produtos orgânicos e a confiança neles passa pela presença ou náo de seres não humanos. No anterior trabalho de Truninger (2013) sobre os mecanismos de confiança nos 'bio', muitas vezes os consumidores utilizavam o 'teste da minhoca' para comprovar a legitimidade e autenticidade daqueles alimentos. Se tinha bicho, era orgânico; se não tinha, não era orgânico.

Para além da presença ou não de bichinhos ou minhocas, mais uma vez, e como comprovado noutros estudos (PORTILLO; CASTAÑEDA, 2011), a experiência sensorial é uma relevante base na construção da confiança alimentar. $\mathrm{O}$ sabor, a textura, as cores são características que atestam a qualidade dos produtos orgânicos, que é valorizada pelos consumidores. Também nos grupos focais, os participantes afirmaram que o sabor é um fator de distinção entre os produtos orgânicos e os convencionais e que é uma das razóes para procurarem por eles. Para muitos, os alimentos ficam com um aspeto menos perfeito ou têm um tamanho reduzido face aos produtos comuns do supermercado. Para outros, têm um aspeto mais atrativo, principalmente quando vendidos nas redes varejistas ou quando estão embalados - o que atrai, mas causa alguma confusão, uma vez que os produtos de agricultura familiar ou caseira são considerados menos bonitos.

Nesse sentido, alguns participantes afirmaram que procuram alimentos menos bonitos, nomeadamente numa cooperativa de consumidores - Fruta Feia -, onde são colocados à venda alimentos que não têm os critérios de qualidade estética para serem vendidos nas grandes redes varejistas. Os pequenos produtores vendem esses produtos com tamanho e calibre 
menores e de aspeto mais 'feio' a essa cooperativa, que depois recebe os consumidores para recolher os seus cabazes com frutas e legumes variados, da época e de produção local. Para alguns dos participantes, esses alimentos lembram-lhes os produtos orgânicos, achando-os muito próximos de uma agricultura orgânica porque é mais saborosa. Esse tipo de mercado mais alternativo é muito valorizado por aproveitar vegetais e frutas que seriam desperdiçados de outra forma, e por ter preços mais baixos.

No geral, os participantes afirmaram que estão disponíveis para confiar nos mecanismos de controlo e fiscalização da agricultura orgânica e que estes são relevantes para manter a presença de tóxicos associados à produção agrícola (pesticidas, herbicidas) abaixo de níveis prejudiciais à saúde.

Quero acreditar que as próprias empresas já têm uma monitorização da qualidade do produto e que façam algum tipo de testes do que vão vender... Mas podem ou não preocupar-se, consoante a empresa. (Grupo focal dos jovens sem filhos).

Em relação aos pesticidas e químicos que são usados na EU, estão normalizados, não vão ser inócuos, mas hão de ter uma percentagem mais reduzida. (Grupo focal de baixa renda).

Tem que ser, senão a $A S A E$ [Autoridade portuguesa para o controlo sanitário e segurança alimentar] andava em cima... Não nos pode fazer assim tão mal senão não era autorizada a venda. Mas claro que não fazem bem os corantes e conservantes... (Grupo focal de jovens sem filhos).

Por outro lado, alguns mostraram ter dúvidas sobre quem fiscaliza as questóes de segurança alimentar em Portugal e se essa fiscalização é eficiente: "Deve ser algo relacionado à agricultura que faz o controle... Até que ponto chega a todos os alimentos??' (Grupo focal de jovens sem filhos).

Os participantes revelaram ter também algum receio do potencial efeito do consumo acumulado a longo prazo e reconhecem manter algumas práticas de segurança ou estratégias de redução da exposição, em particular a lavagem das frutas e legumes ou a remoção da casca (que está em contacto direto com potenciais químicos sintéticos). Para além disso, procuram produtos identificados como estando menos expostos aos 'químicos', por exemplo, os produtos da época, aqueles que são comprados diretamente ao produtor, ou os produtos nacionais. 
Já vi reportagem sobre pesticidas que usavam na Argentina e o que aconteceu com as pessoas que lidam com os pesticidas... Pode ser prejudicial à saúde no futuro... (Grupo focal de baixa renda).

O problema principal está no facto dos químicos estarem presentes praticamente em tudo o que comemos. Não significa que uma maça fará mal, mas a longo prazo e com a continuação diária... (Grupo focal de jovens sem filhos).

Lavo com água e vinagre, é um desinfetante geral. (Grupo focal de mulheres com crianças).

Apesar das preocupaçóes alimentares, nem todos os participantes prestam atenção à informação alimentar presente nos rótulos dos produtos, alguns porque reconhecem que a leitura dos rótulos lhes é confusa, preferindo guiar-se pelas marcas que já conhecem. A leitura dos rótulos surge sobretudo quando compram produtos pela primeira vez ou quando comparam a qualidade entre produtos diferentes. No grupo focal de baixa renda, alguns participantes admitiram só olhar para o rótulo na altura em que consomem o produto, posteriormente à aquisição.

[Os rótulos] É uma confusão! (Grupo focal de mulheres com crianças).

Já sei quais as marcas em que confio e é por essas que vou. (Grupo focal de mulheres com crianças).

Normalmente vejo depois de ter comprado, quando estou a consumir! (Grupo focal de baixa renda).

Os poucos participantes que admitiram olhar para os rótulos, fazemno para saber o prazo de validade do alimento que estáo a comprar. No entanto, salientam alguns outros ingredientes ou elementos a que prestam atenção, tais como a quantidade de açúcar, sal ou gorduras, se contêm aditivos alimentares (e.g., corantes, conservantes, aditivos identificados pelo número E). No grupo focal dos jovens, notamos uma preocupação pela procura de produtos aditivados com proteínas por razôes de saúde, desporto, ou por questóes de cosmética/estética (e.g., aumento de massa muscular, ajuda para ficar com um corpo considerado desejável e tonificado).

Vejo a data de validade e se estiver muito próximo já não compro. (Grupo focal de mulheres com crianças). 
'E's fujo. Se vou comprar alguma coisa, olho para o rótulo e vejo uns 10 'E's, tento evitar. (Grupo focal de jovens sem filhos).

\section{Significados, rotulagem e sistemas de confiança: o inquérito por questionário}

A generalidade dos 1.600 inquiridos que participaram no inquérito por questionário aplicado no final de 2018 mostrou-se bastante familiarizada com o conceito de agricultura orgânica (TRUNINGER et al., 2019). Ao contrário do que sucedia em anteriores inquéritos sobre essa matéria aplicados em finais do século XX e inícios do século XXI (FERREIRA de ALMEIDA, 2004), passados quase 20 anos, os portugueses apresentam percentagens de "não sabe/não responde" muito baixas $(5,6 \%)$ - o que significa que o conceito de agricultura orgânica já está popularizado entre a população portuguesa (TRUNINGER et al., 2019).

Porém, como veremos a seguir, existe ainda uma percentagem considerável que confunde esses produtos com os que se cultivam em 'casa' (nas hortas ou jardins), resultado também encontrado nos grupos focais analisados na secção anterior. Contudo, apesar de ainda haver alguma confusão nas representaçóes dos consumidores (tal como as que existiam no início dos anos 2000, ver TRUNINGER, 2010), podemos notar uma mudança no nível de conhecimento desses produtos. Para tal, as estatísticas sobre produçáo e consumo desses alimentos ajudam, em parte, a explicar o aumento do conhecimento entre a população. De facto, a generalização desses produtos no mercado nacional nas últimas duas décadas veio facilitar o acesso e a penetração desses alimentos nas grandes redes varejistas, sobretudo nas áreas metropolitanas, e a preços mais competitivos do que os praticados no passado.

Os significados mais frequentes associados a esses produtos remetem tanto para aqueles que são regulados e aprovados através de sistemas de certificação $(49,4 \%)$ como para os que são oferecidos pelos familiares, amigos e vizinhos (48,6\%). Mais abaixo, os 'bio' são ainda associados à produção própria $(39,8 \%)$ e aos produtos cuja origem é de confiança, mesmo que não estejam certificados $(31,7 \%)$. Apenas $3,7 \%$ dos portugueses não confiam nesses produtos, já que duvidam que seja possível produzir alimentos 
totalmente livres de químicos (Figura 1) (TRUNINGER et al., 2019), uma desconfiança que também detectámos nos grupos focais.

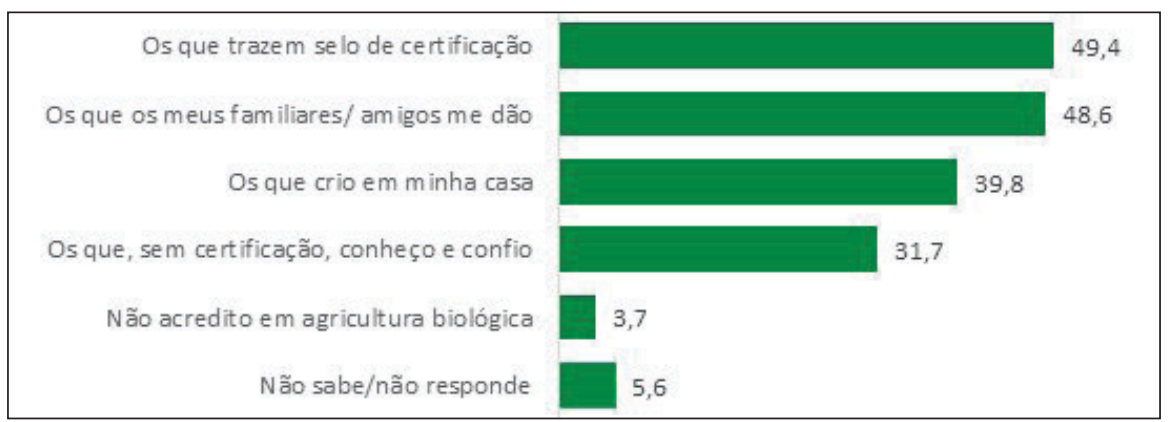

Figura I - Definição dos produtos de agricultura orgânica (\% de inquiridos) Fonte: Segundo Grande Inquérito sobre Sustentabilidade (2018).

Esses diferentes significados de agricultura orgânica tendem a surgir em grupos sociais concretos. Enquanto os sistemas de certificação oficial têm mais peso entre as pessoas com escolaridade e renda mais elevados e entre os residentes das áreas metropolitanas, os significados com base nas redes de conhecimento interpessoal tendem a ser mais frequentes entre os que habitam nas zonas rurais e os que têm escalóes mais baixos de renda (TRUNINGER et al., 2019). Confirma-se, assim, a manutenção do estatuto ambíguo dos produtos orgânicos na sociedade portuguesa. Tal como nos grupos focais, também no inquérito pudemos verificar que os produtos orgânicos são aqueles que os inquiridos, eles próprios ou as suas redes de conhecimento, produzem nas pequenas hortas situadas em espaço rural. Mesmo que haja potencial contaminação cruzada ou a utilização de um ou outro produto químico sintético (muitas vezes desvalorizado), essa produção é considerada 'caseira', 'familiar', 'do campo' e, portanto, associada como sendo mais natural, segura e de confiança (TRUNINGER et al., 2019).

Daí a ideia bastante consensual de que os alimentos de origem orgânica trazem vários benefícios (e.g., mais confiáveis, melhores para a saúde e para o ambiente, promovem o desenvolvimento local; $M=4,01$, escala de 5 pontos), mas que são mais caros e difíceis de encontrar nas lojas 
$(\mathrm{M}=4,12$, escala de 5 pontos) (TRUNINGER et al., 2019) (Figura 2). Nesse âmbito, acrescente-se que os portugueses que mais atribuem benefícios à agricultura orgânica são também os que a consideram pouco acessível: as mulheres, os que têm o grau de ensino superior, que habitam em áreas urbanas e que pertencem aos escalóes etários entre os 25 e 44 anos. No que concerne à rotulagem dos produtos, verificamos que $21 \%$ dos inquiridos reconhecem o certificado de agricultura orgânica, sobretudo entre as mulheres, os mais jovens, os mais escolarizados, os que têm rendimentos mais elevados e os que residem com crianças e adolescentes.

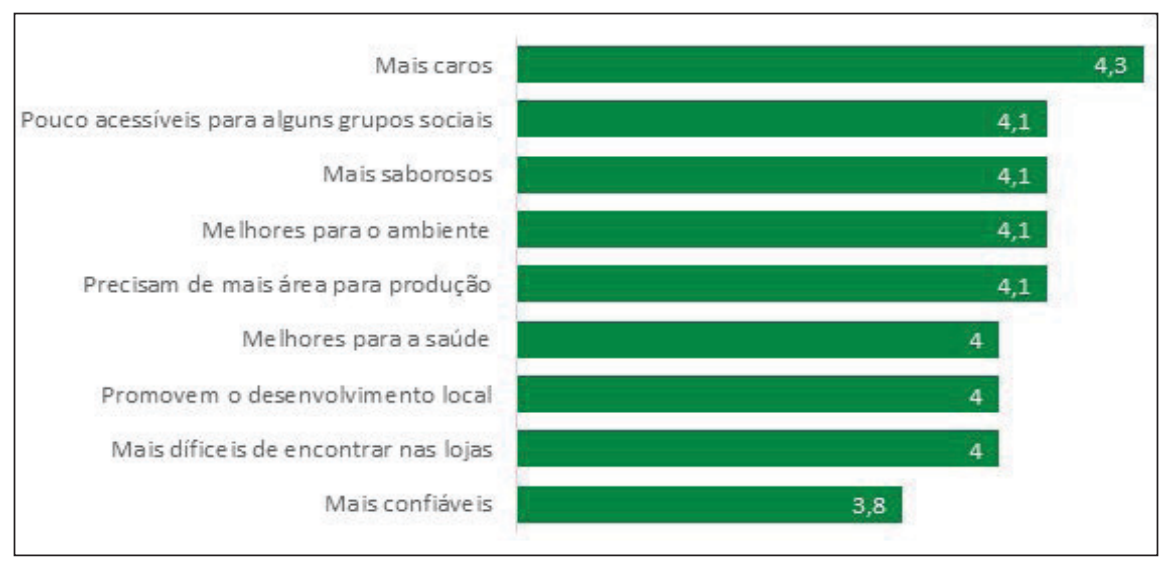

Figura 2 - Significados sobre os produtos de agricultura orgânica (valores médios, escala de 5 pontos) Fonte: Segundo Grande Inquérito sobre Sustentabilidade (2018).

Também procurámos saber se, para além de reconhecerem os símbolos de certificação, os inquiridos alguma vez os utilizavam nas suas compras. O símbolo da agricultura orgânica, que é o mais reconhecido, acaba por não ser dos mais utilizados no ato de compra. De facto, a certificação da agricultura orgânica é importante, mas não determinante para os consumidores de produtos orgânicos - o que aponta para a necessidade de se entender o valor desse rótulo e as suas implicaçôes e garantias -, havendo também a percepçáo da inacessibilidade desses produtos (por exemplo, alimentos mais caros), o que poderá justificar a sua menor utilização quotidiana. 
Em suma, o conceito de agricultura orgânica já está bastante familiarizado entre os portugueses, embora persistam alguns equívocos em relação ao seu significado: sobretudo entre os menos escolarizados, os mais velhos e os residentes em zonas rurais, que tendem a referir menos os sistemas de certificação. No entanto, os produtos de agricultura orgânica são, por um lado, consensualmente associados a benefícios para a saúde e à sustentabilidade ambiental, mas, por outro lado, a uma menor acessibilidade, que desencoraja o seu consumo. Apesar da familiaridade com o conceito, apenas cerca de $20 \%$ dos portugueses reconhecem o símbolo de certificação de agricultura orgânica, muito associado ao aumento da escolaridade e do rendimento, às camadas mais jovens e à presença de menores no agregado.

\section{Conclusão}

O sector da agricultura orgânica, tanto internacionalmente como em Portugal, tem visto as suas áreas de produção, cotas de mercado e número de consumidores a crescer consideravelmente nos últimos anos. Na União Europeia, o enquadramento legal desse modo de produção data do início dos anos 90 do século XX, mas ao longo dos anos essa legislaçáo tem sido alvo de várias alteraçôes, estando prevista para 2021 uma renovação do atual enquadramento legal.

Em conjunto com outras alternativas alimentares (e.g., redução da proteína animal, Dieta Mediterrânica), esse sistema agrícola e de produção animal enquadra-se nos esforços de resposta aos apelos para uma transformação dos hábitos alimentares em nível mundial, promovendo hábitos com menor impacto tanto no ambiente como na saúde.

Apesar do enquadramento legal apertado na utilização de químicos sintéticos, no controlo dos usos da água, no manuseamento do solo, na garantia de princípios de bem-estar animal, o facto de o sector ter crescido e massificado de forma muito rápida faz com que surjam, por vezes, situaçóes de fraude ou de controvérsia em torno do rigor da fiscalização e certificação desses produtos. Por exemplo, em Portugal algumas notícias vieram a público sobre situaçóes de fraude nesse sector. A divulgação dessas notícias, mesmo que as fraudes tenham acontecido apenas em $3 \%$ ou $4 \%$ dos casos, não deixam de ter um impacto na reputação dos produtos 
orgânicos, aumentando a desconfiança dos consumidores no sector. As falhas dos sistemas periciais, técnicos e científicos no controlo e monitorização da produção alimentar orgânica, mesmo que tenham ocorrido excecionalmente, quando são divulgadas acabam por aumentar a desconfiança e a falta de credibilidade na origem da produção desses alimentos.

Como tal, os consumidores acabam por recorrer a outros sistemas e mecanismos de monitorização e controlo, que vão muito além do conhecimento científico e pericial que informa os critérios de fiscalização da agricultura orgânica. Essas outras formas de 'conhecer', 'saber' ou 'confiar' que um produto 'bio' é mesmo 'bio' passam pelas relaçóes interpessoais com os produtores, pela própria confiança que os indivíduos depositam na forma como produzem as suas próprias culturas e produçóes caseiras de plantas e animais, ou ainda pela experiência quotidiana com esses produtos. O conhecimento interpessoal com o produtor, o conhecimento acumulado com base na experiência de produzir (ou ver produzir) alimentos de qualidade sem recurso a químicos sintéticos (ou não abusando muito destes), ou até o conhecimento baseado nos sentidos (e.g., sabor, aparência, cheiros), ajudam os consumidores a construir mecanismos de confiança alternativos aos rótulos e certificados orgânicos.

Tanto os dados qualitativos através dos grupos focais como os quantitativos recolhidos através do Segundo Grande Inquérito sobre Sustentabilidade, aplicado em 2018, reforçam a existência de alguma ambiguidade na definição de produtos orgânicos por parte dos consumidores portugueses. Se é certo que uma grande percentagem da população portuguesa conhece e já ouviu falar de produtos orgânicos, também é certo que ainda os confunde com os produtos da agricultura mais familiar, caseira, tradicional de pequena escala, afastada das cidades e feita em espaço rural. Este tipo de agricultura está longe de ser considerada orgânica, pois não obedece aos critérios e princípios oficiais e legais, mas os consumidores muitas vezes têm mais confiança nesses produtos 'caseiros', que cultivam eles próprios, ou que recebem das suas redes familiares ou de amigos, do que naqueles que se vendem nas grandes redes varejistas. Os consumidores acabam por utilizar uma série de estratégias e mecanismos para construir uma relação de confiança com os alimentos orgânicos, que passam tanto 
pelo conhecimento pericial inscrito num certificado e num logotipo como pelo conhecimento tácito, leigo, experiencial e sensorial que têm com esses alimentos no seu quotidiano.

\section{Referências}

BECK, U. Risk Society - Towards a New Modernity. Londres: Sage, 1992.

BILDTGARD, T. Trust in food in modern and late-modern societies. Social Science Information, v. 47, n. 1, p. 99-128, 2008.

COMISSÃO EUROPEIA. Organic Farming in the EU: a fast growing sector. EU Agricultural Markets Brief, n. 13, mar. 2019.

FERREIRA de ALMEIDA, J. (ed.). Os Portugueses e o Ambiente: II Inquérito Nacional às Representaçôes e Práticas dos Portugueses sobre o Ambiente. Oeiras: Celta Editora, 2004.

GIDDENS, A. The Consequences of Modernity. Cambridge: Polity Press, 1990.

GRAÇA, J. et al. Consumption orientations may support (or hinder) transitions to more plantbased diets. Appetite, v. 140, p. 19-26, 2019. ISSN 0195-6663. DOI https://doi.org/10.1016/j. appet.2019.04.027

GUIVANT, J. Trajetórias das análises de risco: da periferia ao centro da teoria social. Revista de Informaçóes Bibliográficas - Associação Nacional de Pós-Graduação em Ciências Sociais, v. 46, p. 3-38, 1998.

KJAERNES, U.; HARVEY, M.; WARDE, A. Trust in Food: a Comparative and Institutional Analysis. Basingstoke: Palgrave Macmillan, 2007.

LOPES, C. et al. Consórcio IAN-AF. Inquérito Alimentar Nacional e de Atividade Física, IAN-AF 2015- 2016: Relatório de Resultados, Universidade do Porto, 2017. ISBN 978-989-746181-1. Disponível em: https://ian-af.up.pt/sites/default/files/IAN-AF\%20Relat\%C3\%B3rio\%20 Resultados_0.pdf. Acesso em: 23 fev. 2020.

LUHMANN, N. Trust and Power: Two Works by Niklas Luhmann. Chichester: John Wiley \& Sons, 1979.

MISZTAL, B. Trust in Modern Societies: The Search for the Bases of Social Order. Cambridge: Polity Press, 1995.

PORTILLO, F; CASTAÑEDA, M. Certificação e confiança face a face em feiras de produtos orgânicos. Revista de Economia Agricola, v. 58, n. 1, p. 11-21, 2011.

ROE, E. J. Things becoming food and the embodied, material practices of an organic food consumer. Sociologia Ruralis, v. 46, n. 2, p. 104-121, 2006.

SASSATELLI, R.; SCOTT, A. Novel food, new markets and trust regimes: Responses to the erosion of consumers' confidence in Austria, Italy and the UK. European Societies, v. 3, n. 2, p. 213-244, 2001. 
TRUninger, M. O Campo Vem à Cidade: Agricultura Biológica, Mercado e Consumo Sustentável. Lisboa: Imprensa de Ciências Sociais, 2010.

TRUNINGER, M. As bases plurais da confiança alimentar nos produtos orgânicos: da certificação ao 'teste da minhoca'. Ambiente \& Sociedade, v. 16, n. 2, p.81-102, 2013.

TRUNINGER, M. et al. Segundo Grande Inquérito sobre Sustentabilidade: Relatório Executivo. Observa. Instituto de Ciências Sociais da Universidade de Lisboa, 2019.

WILLETT, W. et al. Food in the anthropocene: The EAT-lancet commission on healthy diets from sustainable food systems. The Lancet, v. 393, n. 10170, p. 447-492, 2019.

Recebido 03/02/2020

Aprovado 30/03/2020 


\section{Consumers and organic farming in Portugal: meanings and (dis)trust}

\section{Abstract}

In the last years of the current century, the organic farming sector has seen its production areas, market shares and the number of consumers fast growing. In the European Union, the legal framework for this mode of production dates back to the early 90s of the 20th century, but over the years this legislation has undergone several changes. Despite a tight legal framework, fraud or controversy situations sometimes arise around the inspection and certification of organic products. The flaws in the expert, technical, scientific systems in the control and monitoring of organic food production, even if they occur exceptionally, when they are disclosed by the media, they end up increasing consumers distrust and lack of credibility in the origin and methods of the production of these foods. In this text, based on qualitative and quantitative data, we analyze the meanings that consumers have about organic products, often confusing them with the products that they grow at home or offered to them by their family, friends and family networks. The mechanisms for building a relationship of trust with organic foods are also analyzed, which include both the expert knowledge inscribed on a certificate and a logo, as well as the tacit, lay, experiential and sensory knowledge they have with these foods in their daily lives. It is concluded that consumers use different and multiple strategies, combining expert knowledge with lay knowledge, to ensure that what they ingest in their bodies are really organic products.

Keywords: Organic farming. Consumers. Distrust. Food system. Organic food meanings. 